\section{Lex mercatoria, arbitragem internacional e democracia: reflexões acerca da utilização dos usos do comércio transnacional enquan- to fundamento válido e democrático para a resolução de conflitos por meio da arbitra- gem internacional*}

\section{Lex mercatoria, international arbitration and democracy: think over the usage of the transnational commercial practices as a valid and democratic basis for the resolution of disputes through international arbitration}

\section{Resumo}

Este artigo tem por finalidade analisar a conceituação histórica de lex mercatoria e o ambiente de produção de normas referentes ao comércio internacional fora dos limites de atuação legislativa dos Estados soberanos. O texto trabalhará com a abordagem empreendida por Gunther Teubner quanto a lex mercatoria, e a teoria dos sistemas por Marcelo Neves em relação à definição de uma ordem privada transnacional; e por Rodrigo Broglia Mendes no que diz respeito ao comércio e à arbitragem internacionais sob a ótica da lex mercatoria. Para além da quebra de paradigmas eventualmente decorrente da utilização de normas que não derivam da atuação estatal, o objetivo deste trabalho consiste em compreender se a utilização dos usos do comércio internacional para a resolução de conflitos tende a implicar limitação da experiência democrática no âmbito dos Estados soberanos. A contribuição que se pretende conferir com este texto está na elaboração de uma leitura da lex mercatoria, levando-se em consideração a perspectiva da experiência democrática. Tem-se, com isso, a tentativa de preenchimento de uma lacuna no que se refere à análise prática do que seja a lex mercatoria e a sua aplicação para a resolução de conflitos transnacionais mediante procedimentos arbitrais.

Palavras-chave: Lex mercatória. Comércio transnacional. Arbitragem internacional. Democracia.

\begin{abstract}
This article aims to analyse the historical conception of lex mercatoria and the environment of international trade rules production, beyond the edges of the legislative role on the sovereign States. The text will work with the approach taken by Gunther Teubner on the lex mercatoria and the systems theory; by Marcelo Neves on the definition of transnational private order; and by Rodrigo Broglia Mendes on the international trade and arbitration as seen by lex mercatoria. Further on the breaking frames of the positive law, the article's goal is to understand whether the international trade usages as a decision criteria trend to limit the subjective right of democracy on the sovereign States. The contribution that is intended to confer with this text is to draw up a lex mercatoria reading taking into account guidelines that keep beating the democratic sentiment. It also intends to fill a gap in regard to the practical analysis of what is the lex mercatoria and its practical application to the resolution of international disputes through arbitration proceedings.
\end{abstract}

Keywords: Lex mercatoria. Transnational trade. International arbitration. Democracy. 


\section{Introdução}

Em trabalho intitulado Breaking Frames: Economic Gobalisation and the Emergence of the lex mercato$\mathrm{ria}^{2}$, Gunther Teubner apresenta como questão central perquirir se uma Corte de Justiça de um determinado país soberano poderia/deveria reconhecer a "justiça privada" decorrente da lex mercatoria como forma válida de direito positivo aplicável à resolução de conflitos em relações jurídicas transnacionais. ${ }^{34} \mathrm{O}$ exemplo adotado por Gunther Teubner no mencionado trabalho contempla disputa arbitral internacional no caso que ficou conhecido como "Primary Coal Incorporated vs. Compania Valenciana de Cementos Portland", decidida por meio de arbitragem internacional no ano de 1991. Tal disputa não é importante para o presente trabalho em decorrência da discussão de mérito desta, que quase não é mencionada por Teubner, mas tem importância, porém, em virtude da origem das conclusões que foram adotadas pela corte arbitral e pelos paradoxos que deveriam ser enfrentados pela Suprema Corte francesa para a internalização da decisão em sua jurisdição. Isso ocorre porque a corte arbitral fundamentou o seu entendimento apenas nos "usos do comércio internacional, também conhecidos como

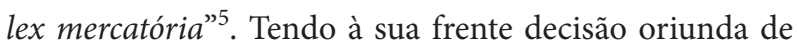

2 TEUBNER, Gunther. Breaking frames: economic globalization and the emergence of Lex mercatoria. European Journal of Social Theory, Liverpool, v. 5, n. 2, p. 199-217. May, 2002. Disponível em: <http://papers.ssrn.com/sol3/ papers.cfm?abstract_id=893143>. Acesso em: 29 jun. 2015.

3 "Should the national court recognize lex mercatoria's "private justice" as a new positive law with transnational validity?" TEUBNER, Gunther. Breaking frames: economic globalization and the emergence of Lex mercatoria. European Journal of Social Theory, Liverpool, v. 5, n. 2, p. 199-217. May. 2002. Disponível em: <http://papers.ssrn.com/sol3/ papers.cfm?abstract_id=893143>. Acesso em: 29 jun. 2015. p. 200.

4 A concepção do vocábulo "transnacionalidade" utilizado para os fins propostos por este trabalho pode ser extraído da noção adotada por Marcelo Neves: "No sentido mais estrito (sem que se negue aqui que haja empregos intermediários), a que dou preferência neste trabalho, a mesma expressão refere-se ao transnacional no sentido proposto por Teubner, que aponta para ordens normativas privadas ou quase públicas que surgem e se desenvolvem no plano global independentemente tanto do Estado e de suas fronteiras quanto de ordens construídas com base em Estados, ou seja, supranacionais e internacionais". NEVES, Marcelo. Transconstitucionalismo. São Paulo: M. Fontes, 2009. p. 84. Tradução livre de: “...les seules usages du commerce international, autrement dénommés lex mercatoria...”

TEUBNER, Gunther. Breaking frames: economic globalization and the emergence of Lex mercatoria. European corte arbitral internacional que adotasse por fundamento os usos e costumes do comércio internacional, deveria o magistrado (francês, no exemplo citado por Teubner) indagar e responder o seguinte: (i) a lex mercatoria é um modelo aceitável de ordem jurídica?; (ii) Como identificar normas jurídicas válidas e aplicáveis na estrutura da lex mercatoria?; E (iii) qual a origem da lex mercatoria? Essas perguntas formuladas por Teubner servem como importantes balizas para se investigar o que seja a lex mercatoria e a estrutura que a comporta.

Vê-se que a análise proposta por Gunther Teubner não é, simplesmente, quanto ao mérito de uma determinada discussão. Sua abordagem se destaca por levar em consideração questões que devem - ou deveriam - ser enfrentadas pelo magistrado da Corte Suprema francesa para admitir a internalização da decisão arbitral em disputa de comércio internacional quando fundamentada não em normas positivadas pelo Estado - hard law mas em usos costumeiros decorrente da atividade mercantil - soft law. No exemplo apresentado, o juiz do Estado percorre um caminho de perquirições e de estudo para tentar descobrir o que seja lex mercatoria. Eventual aceitação da lex mercatoria como um efetivo conjunto normativo de aplicação transnacional não legislado, não positivado, implicaria reconhecer a ocorrência de quebra de paradigmas no Direito, que, nos sistemas jurídicos formalistas, acaba por ser delimitado apenas ao conteúdo efetivamente legislado.

Este trabalho propõe ir um pouco adiante da simples (re)leitura das discussões em torno da lex mercatoria. A questão central que se quer analisar consiste em em saber se a utilização dos usos e costumes do comércio internacional para a resolução de conflitos dele decorrentes pode ser encarada como limitação à experiência democrática nos Estados soberanos envolvidos. O contexto em que inserida a análise cogita e admite a produção de normas fora dos limites de atuação legislativa soberana. Ou seja, pensa-se em um conjunto de normas aplicáveis ao comércio internacional e que, dada a dimensão geralmente apátrida das relações comerciais transnacionais, seriam suficientes para orientar negociações, reger contratos e proporcionar a resolução de conflitos. Todavia, admitir a existência de normas que seriam produzidas

Journal of Social Theory, Liverpool, v. 5, n. 2, p. 199-217. May. 2002. Disponível em: <http://papers.ssrn.com/sol3/ papers.cfm?abstract_id=893143>. Acesso em: 29 jun. 2015. p. 199-200. 
fora da atuação estatal estaria adequado ao que se entende por democracia, especialmente no Brasil? Trata-se, portanto, de leitura do comércio internacional e da arbitragem como forma de resolução válida e eficaz de conflitos sob o espectro do conceito e da experiência da democracia.

Nessa esteira, a primeira seção deste trabalho apresentará a conceituação da lex mercatoria e o que se entende na doutrina como as suas fases. A abordagem empreendida, de cunho estritamente conceitual, tende a demonstrar que os usos e costumes do comércio serviram para regular a negociação entre comerciantes desde o período medieval, utilização que acabou por ser estendida a partir das empreitadas marítimas e da expansão do comércio para além das fronteiras das cidades.

A segunda sessão analisará o insight, a inspiração que permeia a ideia da denominada "nova-nova lex mercatoria", tal como concebido por Gunther Teubner em conformidade com a teoria dos sistemas de Niklas Luhmann. A observação que cabe fazer é que aquele sociólogo alemão propõe mudança de prisma para a compreensão da lex mercatoria, de modo que não se intente compreendê-la como ordem jurídica, senão como um subsistema do sistema jurídico, um conjunto de regras derivadas de fatos da vida e que se propagam por meio da comunicação jurídica racional.

Na terceira sessão, será apresentada a arbitragem enquanto método de resolução de conflito apto a dirimir controvérsias decorrentes dos usos e costumes do comércio transnacional, ou seja, mediante a utilização de categorias que estariam compreendidas na lex mercatoria.

Finalmente, a quarta sessão objetivará cotejar a concepção teuberiana de lex mercatoria com a experiência democrática dos países soberanos. Isso quer dizer que a proposta de pesquisa almejará alternar a tendência do discurso jurídico meramente teórico acerca da lex mercatoria e apresentar análise que busque a fruição do direito à instituições democráticas soberanas.

\section{Lex mercatoria e arbitragem internacional}

A lex mercatoria é entendida como um conjunto de normas costumeiras do mercado, do comércio. São normas informais, ditadas pela prática da mercancia e que não pressupõem qualquer participação essencial do Estado legislador.

A aplicação dos "usos" do comércio surge, logica- mente, com o início de um mercado minimamente organizado, como o que se percebe no período medieval, nas feiras medievais da Europa Continental, em especial na França, na Itália e na Alemanha. Tais "usos” decorriam da experiência e do exercício prático das atividades de comércio. $\mathrm{Na}$ ausência de normas estatais positivadas que regulassem a atuação dos comerciantes, foram se cristalizando práticas costumeiras que, no mais das vezes, possuíam lastro na confiança e na boa-fé. A concepção da lex mercatoria medieval, portanto, partia sempre do ponto de vista do sujeito que ostentava a qualidade, ou o status, de comerciante, e era entendida como uma ordem normativa própria.

A utilização dos usos e práticas do comércio medieval teve considerável expansão a partir da extrapolação do comércio para além dos limites territoriais das cidades medievais. Seu crescimento ocorreu de forma mais considerável a partir das expedições marítimas, especialmente na parte comandada pela Holanda e pela Inglaterra. Nesse país, que desenvolveu o seu direito sobre fundamentos do common law, o conjunto de usos denominado lex mercatoria ganhou especial relevo, de modo que as práticas foram compiladas para consulta e aplicação às relações comerciais no que se denominou Law Merchant ${ }^{6}$. A utilização de tais normas levava em consideração, além dos usos das feiras medievais, as práticas e os costumes imemoriais do comércio internacional já praticado, que eram assentados em diretrizes autônomas em relação a ordens estatais postas e de eficiência normativa tanto para procedimentos de negociação quanto para a resolução de eventuais conflitos.

$\mathrm{O}$ incremento das relações de comércio internacional acabou por fortalecer sistema normativo fundado em costumes, em usos corriqueiros e práticos. E isso ocorreu, em especial, porque se verificou a insuficiência e a ineficácia de normas estatais ou mesmo de direito internacional (oficial) para a condução de negociações e para a resolução de conflitos. Contudo, a contumaz utilização dessas "normas costumeiras" abarcadas pelo que se denominou lex mercatoria medieval acarretou problema de aceitação pelos Estados soberanos. Ora, consideradas as

Na Inglaterra do século XVIII (ano de 1754), Windham Kent Beawes editou o compêndio denominado "Lex Mercatoria Rediviva", também conhecido como "Merchant's Directory", que deveria servir como "a complete guide to all men in business." BEAWES, Wyndham Kent; MORTIMER, Thomas. Lex mercatória rediviva: or, the Merchant's directory. London: J. Rivington, and Sons, 1754. 
bases formais do direito europeu continental, só teria autoridade normativa a norma produzida pelo Estado em sede de atuação legislativa e que possuísse lastro hierárquico em relação a outras normas já positivadas. Além disso, o descrédito na lex mercatoria decorreu do fato de que ela não possuía critérios operacionais claros, tampouco era decorrente de atos praticados em uma efetiva societas mercatorum, ou seja, em uma sociedade de mercadores estruturada.

Com a finalidade de manter a eficácia normativa, evoluiu-se, então, para uma nova concepção teórica do que seja lex mercatoria. Dessa vez, considerava-se por relevante o desafio enfrentado pela economia nos anos de 1960/1970 e pelo direito comercial estatal relativamente “à inadequação das regras de direito das ordens estatais ou do direito internacional tradicional para disciplinar as condutas e os conflitos no plano dos negócios transnacionais"7. Esse novo pensamento concebia os usos e costumes do comércio internacional não como ordem jurídica em si, mas como metodologia que permitiria consolidar e padronizar práticas do comércio internacional, notadamente, com o escopo estabelecer standards de procedimentos e expectativas. Tal visão dos usos do comércio passou a ser denominada, em sede teórica, "nova lex mercatoria", de modo que se pudesse distingui-la terminologicamente da lex mercatoria medieval.

$\mathrm{Na}$ "nova lex mercatoria", os avanços foram verificados a partir da existência de organismos e de associações internacionais e da possibilidade de incremento da participação desses agentes no processo de compilação de procedimentos, ou seja, na elaboração de compêndios normativos que estabelecessem métodos de negociação, de contratação e de resolução de conflitos. Nesse ambiente surgiram codificações como os Princípios do International Institute for the Unification of Private Law (UNIDROIT) aplicáveis aos contratos internacionais do comércio e se consolidou, no cenário internacional, a atuação de agentes como a United Nations Commission on International Trade Law (UNCITRAL), o International Chamber of Commerce (ICC), o Transatlantic Trade and Investment Partnership (TTIP), e o Hague Conference on Private International Law $(\mathrm{HCCH})$.

Em relação à "nova lex mercatoria", é importan-

MENDES, Rodrigo Octávio Broglia. Arbitragem, lex mercatoria e direito estatal: uma análise dos conflitos ortogonais do direito transnacional. São Paulo: Quartier Latin, 2010. p. 63 . te considerar, ainda, o fato de que é nesse ambiente que se destaca a atuação de grandes multinacionais no mercado e no comércio internacionais, na medida em que celebram contratos e realizam negócios no mundo todo. Essa expansão da atividade da mercancia para além das fronteiras do Estado teria produzido, ainda, o efeito de aguçar o interesse na evolução das práticas da arbitragem internacional, em especial a partir do “ingresso nesse campo dos escritórios de advocacia americanos e ingleses que tinham uma certa aversão à ideia de uma lex mercatoria defendida pelos pioneiros da Europa continental e que levou a uma crescente sofisticação do procedimento arbitral, assemelhando-o a procedimentos judiciais"8.

Importa referir, também, que, na linha do que a lex mercatoria apresenta como estrutura normativa para o setor mercante, surgem conjuntos normativos específicos para diversos setores de interação humana transnacional, como é o caso da lex laboris para as relações de trabalho; da lex petrolea para o setor de combustíveis fósseis; da lex sportiva para o setor esportivo; os consagrados direitos humanos no que se refere ao respeito ao homem; dentre outros.

O surgimento dessas normas específicas decorrentes de usos e costumes de um determinado setor estaria ligado a "agitações" no seu respectivo núcleo de interesse, a implicar reverberação e multiplicação das suas características. Esse entendimento é defendido por Gunther Teubner, que se apoia na teoria dos sistemas desenvolvida por Niklas Luhmann e nos estudos sociológicos de Eugen Ehrlich acerca da região da Bukowina, então pertencente ao Império Austro-Húngaro - hoje território da Ucrânia. Teubner é o autor do texto base adotado para a reflexão ora proposta, como já registrado na introdução deste trabalho, e é da percepção dessas “agitações” que ele extrai o insight que o guia para a compreensão de uma lex mercatoria fundada não como ordem jurídica ou como um conjunto de princípios e diretrizes. Sua proposta, em síntese, consiste em entender a lex mercatoria como um aglomerado de fatos de vida que repercute no sistema jurídico por meio de comunicações racionais.

\subsection{Lex mercatoria à visão de Gunther Teubner}

Gunther Teubner é um sociólogo alemão que se

8 MENDES, Rodrigo Octávio Broglia. Arbitragem, lex mercatoria e direito estatal: uma análise dos conflitos ortogonais do direito transnacional. São Paulo: Quartier Latin, 2010. p. 62. 
dedica a pesquisar temas relacionados à área jurídica. Seu primeiro texto de relevo acerca da lex mercatoria é intitulado "A Bukowina Global sobre a Emergência de um Pluralismo Jurídico Transnacional" e foi publicado originalmente em 1996. Sua reflexão acerca dos efeitos jurídicos da globalização é iniciada com uma indagação acerca da possibilidade de uma eventual ordem jurídica mundial.

Quem tem razão: Bill Clinton ou Eugen Ehrlich? Ambos acalentam a idéia utópica de um ordenamento jurídico mundial, o ex-presidente dos EUA tanto quanto o hoje em dia amplamente esquecido professor de direito da cidade de Czernowitz, da distante Bukowina, que desenvolveu nessa remota paragem da Monarquia austro-húngara a sua idéia do direito vivo.

Assim como a Pax Americana, a Pax Bukowina é a visão de uma ordem fundada na paz mundial e de um ordenamento jurídico mundial. Mas Clinton e Ehrlich discordam quanto ao caminho em direção ao novo direito mundial. Na nova ordem mundial de Bill Clinton, o novo direito comum para o mundo deverá vir no bojo da política internacional. O ordenamento jurídico mundial do ex-presidente dos EUA deverá assentar na gestão política de um sistema de blocos regionais.

Em contrapartida, na "Bukowina global", de Eugen Ehrlich, justamente não é a política, mas a própria sociedade civil que cria para si mesma o seu direito vivo - a uma distância relativa, e mesmo em oposição à política. ${ }^{10}$

A ideia de um "direito vivo", ou seja, oriundo da própria sociedade e que regesse as relações na comunidade, mostrou-se indutora das reflexões de Gunther Teubner, que admite que a globalização conduz à formação de global villages em que o direito vivo é reproduzido naturalmente, da periferia para o centro.

9 TEUBNER, Gunther. Global Bukowina: legal pluralism in the world-society. In: (Ed.). Global law without a state. Aldershot: Dartmouth, 1996. p. 3-28. Disponível em: <http://papers.ssrn.com/sol3/papers.cfm?abstract_ $\mathrm{id}=896478>$. Acesso em: 29 jun. 2015. Versão em português em: TEUBNER, Gunther. A Bukowina global sobre a emergência de um pluralismo jurídico transnacional. Impulso, Piracicaba, v. 14, n. 33, p. 9-31, 2013. Disponível em: <http://www.unimep.br/phpg/editora/revistaspdf/imp33art01.pdf>. Acesso em: 29 jul. 2015.

10 TEUBNER, Gunther. Global Bukowina: legal pluralism in the world-society. In: (Ed.). Global law without a state. Aldershot: Dartmouth, 1996. p. 3-28. Disponível em: <http://papers.ssrn.com/sol3/papers.cfm?abstract_ $\mathrm{id}=896478>$. Acesso em: 29 jun. 2015. Versão em português em: TEUBNER, Gunther. A Bukowina global sobre a emergência de um pluralismo jurídico transnacional. Impulso, Piracicaba, v. 14, n. 33, p. 9-31, 2013. Disponível em: <http://www.unimep.br/phpg/editora/revistaspdf/imp33art01.pdf >. Acesso em: 29 jul. 2015
Disso resulta a nossa tese principal: o direito mundial desenvolve-se a partir das periferias sociais, a partir das zonas de contato com outros sistemas sociais, e não no centro de instituições de Estados-nações ou de instituições internacionais. As global villages de áreas sociais parciais autônomas formam a nova Bukowina da sociedade mundial, na qual o direito vivo, de Eugen Ehrlich, ressurge nos nossos tempos. Aqui se localiza a razão mais profunda do fato de que nem as teorias políticas nem as teorias institucionais do direito, mas tão somente uma teoria - renovada - do pluralismo jurídico, pode fornecer explicações adequadas da globalização do direito. ${ }^{11}$

A linguagem utilizada por Teubner demonstra que a sua concepção de direito assenta-se na compreensão de sistema jurídico, tal como construído por Niklas Luhmann. Embora não seja objeto deste trabalho estudar, minuciosamente, a sofisticada teoria dos sistemas, é importante tecer breves considerações, um resumo mesmo, para que seja possível apreender - ou pelo menos tentar - o fio condutor das conclusões de Teubner.

Em síntese, pode-se inferir que, segundo a teoria dos sistemas luhmanniana e teuberiana, o sistema jurídico seria uma estrutura fechada, o que não o impediria de interagir com outros sistemas que permeiam a vida em sociedade. Por essa razão, diz-se que o sistema jurídico reproduziria o conteúdo em si contido e admitiria contribuições de outros sistemas, sempre mediante comunicação consciente e racional. É essa forma de comunicação que possibilitaria agregar em um sistema informações extraídas de outro(s) sistema(s). Essa interação entre sistema acarretaria a acumulação de conteúdo estrutural, donde se extrai a ideia de um acoplamento de estruturas $^{12}$. No que se refere aos contratos transnacionais, que decorreriam do acoplamento estrutural dos sistemas jurídico e econômico, haveria o compartilhamento de

11 TEUBNER, Gunther. Global Bukowina: legal pluralism in the world-society. In: (Ed.). Global law without a state. Aldershot: Dartmouth, 1996. p. 3-28. Disponível em: <http://papers.ssrn.com/sol3/papers.cfm?abstract_ $\mathrm{id}=896478>$. Acesso em: 29 jun. 2015. Versão em português em: TEUBNER, Gunther. A Bukowina global sobre a emergência de um pluralismo jurídico transnacional. Impulso, Piracicaba, v. 14, n. 33, p. 9-31, 2013. Disponível em: <http://www.unimep.br/phpg/editora/revistaspdf/imp33art01.pdf $>$. Acesso em: 29 jul. 2015.

12 Marcelo Neves bem sintetiza a ideia de "acoplamentos estruturais" concebida pela teoria dos sistemas luhmanniana: "Os acoplamentos estruturais constituem fundamentalmente mecanismos de interpenetrações concentradas e duradouras entre sistemas sociais". NEVES, Marcelo. Transconstitucionalismo. São Paulo: M. Fontes, 2009. p. 37. 
expectativas a permitir a redução de complexidades do conjunto de interações exigidas pelo contrato.

A comunicação, segundo a teoria dos sistemas, ocorreria sempre por meio de códigos. No caso do sistema jurídico, os códigos utilizados para a comunicação consciente e racional são expressos pelos vocábulos "lícito" e "ilícito". Os códigos do sistema jurídico operam por meio de programas, ou critérios, em que seu conteúdo é reverberado, como são exemplo para o presente estudo os programas da territorialidade e da setorialidade. $\mathrm{O}$ destaque para esses dois programas ocorreria porque é na territorialidade e na setorialidade que se verificariam eventuais impactos ou agitações causados pela lex mercatoria. Para Teubner, uma vez adotado o critério da setorialidade, não haveria lugar para a tradicional teoria jurídica das fontes, que é ligada ao programa da territorialidade, e nem para a hierarquização de normas. $\mathrm{Ou}$ seja, no sistema jurídico o código lícito/ilícito repercute para os interessados, sem vinculação a limites territoriais, quando utilizado o programa de setorialidade, que é o programa em que operam a lex mercatoria, a lex sportiva, a lex laboris, a lex petrolea etc.

Sob esse espectro da setorialidade, o comércio internacional possuiria fundamento válido e eficaz na lex mercatoria, e estaria a movimentar-se mediante a utilização de padrões, de standards contratuais que gerariam e assegurariam expctativas, sem que houvesse necessária ligação com a atividade estatal. Partindo-se da compreensão de que não há, na lex mercatoria, norma positiva estatal e de que não existe negócio jurídico no vácuo ${ }^{13}$, o que estaria a reger, então, os contratos de comércio internacional? Surge, nessa perspectiva, a problemática, ou paradoxo, do contrato autovalidante: a lex mercatoria não se sustentaria em seus próprios usos tradicionais, mas decorreria também do reconhecimento de validade transnacional de standards ou padrões de contratação; “isto é, a partir da construção de expectativas de que esse standard será aceito como uma regra por aqueles que se lançarem na contratação transnacional"14. No mercado internacional são, assim, criados contratos que possuem

13 MENDES, Rodrigo Octávio Broglia. Arbitragem, lex mercatoria e direito estatal: uma análise dos conflitos ortogonais do direito transnacional. São Paulo: Quartier Latin, 2010. p. 82.

14 MENDES, Rodrigo Octávio Broglia. Arbitragem, lex mercatoria e direito estatal: uma análise dos conflitos ortogonais do direito transnacional. São Paulo: Quartier Latin, 2010. p. 82. certas "fórmulas contratuais", standards de contratação que geram expectativas de regras para todos os que se lançarem ao comércio transnacional. Há efetivo rompimento com estruturas do direito estatal e com qualquer ordem jurídica positivada.

A construção dos standards contratuais no comércio internacional estaria fincada, assim, em três pressupostos, que se revestiriam da condição de cláusulas não contratuais. Em primeiro lugar, adota-se por estratégia de validação dos contratos de comércio internacional a criação de hierarquias entre suas normas, entre seus comandos; o padrão contratual deverá decorrer, assim, de práticas que garantam ou que pelo menos objetivem assegurar a execução dos contratos, assim considerados a composição dos comandos obrigacionais e dos comandos de sancionadores. Em segundo lugar, deve-se temporalizar a autovalidação do contrato, de modo que o contrato "report[e]-se a uma estandardização preexistente de regras, referindo-as ao futuro, à regulação de um potencial conflito e, com isso, torn[e] o contrato apenas um elemento num processo contínuo de autocriação, reflexivo" ${ }^{15}$. Em terceiro lugar, há a estratégia de externalizar a autovalidação, de modo que a resolução de conflitos ocorra por instituições que sejam externas ao contrato. Nessa terceira estratégia, situa-se a previsão de que os conflitos sejam resolvidos por arbitragem, e não por autoridades ou tribunais estatais.

A lex mercatoria seria, portanto, na visão de Teubner, um subsistema com programas próprios que estaria a "gravitar" ao redor do sistema jurídico. Seu núcleo seria composto por um órgão decisional a realizar o papel que no sistema jurídico caberia ao Judiciário e seu conteúdo, por cláusulas não contratuais, fundadas nos usos, costumes e práticas do comércio internacional.

\subsection{Arbitragem internacional à Gunther Teubner}

Os contratos de comércio internacional, na medida em que possuem conteúdo padronizado, tenderiam a fugir das regras estatais positivadas. Com isso, os conflitos decorrentes dessas relações comerciais internacionais submetem-se à arbitragem para a resolução dos conflitos.

A arbitragem é um modo de resolução de conflitos entre sujeitos particulares, ou entre sujeitos particulares e

5 MENDES, Rodrigo Octávio Broglia. Arbitragem, lex mercatoria e direito estatal: uma análise dos conflitos ortogonais do direito transnacional. São Paulo: Quartier Latin, 2010. p. 83-84. 
públicos quando os conflitos emerjam de relações jurídicas em que os entes ou as autoridades públicos não atuem sob o escudo de prerrogativas legais. O espectro de aplicação da arbitragem pode ser tanto interno a um determinado território ${ }^{16}$ quanto externo, oportunidade em que se depara com a arbitragem internacional. Consideradas as vantagens decorrentes desse método de composição de litígios, como é o caso da celeridade, da neutralidade e do menor formalismo, "a arbitragem constitui actualmente um modo fundamental - para alguns mesmo o modo normal - de resolução dos litígios emergentes das relações mercantis internacionais" ${ }^{\prime 17}$.

A adoção da arbitragem tem se mostrado um meio atraente e eficaz de resolução de disputas no comércio internacional. O presidente da ICC John Beechey destaca que a arbitragem

\begin{abstract}
remains worldwide a principal medium for dispute resolution, particularly in a cross-border context, where parties are disinclined to accept the jurisdiction of the home court of one or the other, whether for political or commercial reasons, or whether because a pragmatic assessment leads regrettably, to the conclusion that a fair and rigorous application of the relevant law to the relevant facts, might not necessarily be taken for granted. ${ }^{18}$
\end{abstract}

A arbitragem situa-se, pois, como uma das estratégias de autovalidação dos contratos de comércio internacional situados no que seria o programa setorial da lex mercatoria, ou seja, aos usos práticos e imemoriais do comércio internacional. E o é porque, de acordo com a estrutura do sistema jurídico concebido por Gunther

16 No Brasil, a Lei 9.307, de 23/9/1996 dispõe sobre a arbitragem, que teve o seu âmbito de aplicação ampliado pelas alterações implementadas pela Lei 13.129, de 26/5/2015. BRASIL. Lei $n^{\circ}$ 9.307, de 23 de setembro de 1996. Dispõe sobre a arbitragem. Disponível em: <http://www.planalto. gov.br/ccivil_03/leis/L9307.htm>. Acesso em: 27 ago. 2015; BRASIL. Lei $n^{\circ} 13.129$, de 26 de maio de 2015. Altera a Lei no 9.307, de 23 de setembro de 1996, e a Lei no 6.404, de 15 de dezembro de 1976, para ampliar o âmbito de aplicação da arbitragem e dispor sobre a escolha dos árbitros quando as partes recorrem a órgão arbitral, a interrupção da prescrição pela instituição da arbitragem, a concessão de tutelas cautelares e de urgência nos casos de arbitragem, a carta arbitral e a sentença arbitral, e revoga dispositivos da Lei no 9.307, de 23 de setembro de 1996. Disponível em: <http://www.planalto.gov.br/ccivil_03/_Ato20152018/2015/Lei/L13129.htm>. Acesso em: 27 ago. 2015.

17 VICENTE, Dario Moura. Da arbitragem comercial internacional: direito aplicável ao mérito da causa. Coimbra: Coimbra, 1990. p. 2.

18 WALD, Arnoldo; LEMES, Selma Ferreira (Coord.). Arbitragem comercial internacional: a Convenção de Nova Iorque e o direito brasileiro. São Paulo: Saraiva, 2011. p. 17.
Teubner, deveria haver, necessariamente, um núcleo decisional no núcleo do sistema e na sua periferia, ao passo que, no centro do sistema jurídico, o núcleo decisional do código lícito/ilícito é exercido, em regra, pelo Poder Judiciário, na periferia em que situada a lex mercatoria cabe à arbitragem exercer o papel decisional.

Os contratos transnacionais tendem a ser "apátridas", sem dedicar obediência a nenhum ordenamento jurídico estatal específico. Embora assim o sejam, é difícil cogitar de um contrato sem um embasamento jurídico que lhe dê sustentação quanto à estabilização de expectativas e ao cumprimento das obrigações. Teubner trata essa situação sob a ótica da autovalidação do contrato transnacional. Ou seja, esses contratos possuem determinadas fórmulas padronizadas, standards que objetivam assegurar expectativas. Esses standards são embasados em "costumes", em elementos não contratuais. Estes, por sua vez, organizam-se, hierarquicamente, em regras primárias (conduta) e secundárias (consequências); exteriorizam uma projeção para o futuro; e externalizam critérios de validade e de resolução de conflitos por meio da arbitragem. Standards adicionais são conferidos por órgãos internacionais que exercem funções semelhantes ao do Legislativo.

As figuras 1. e 2. abaixo objetivam demonstrar visualmente como seriam o núcleo do sistema jurídico e a periferia ligada à lex mercatoria, respectivamente.

Figura 1 - Núcleo do sistema jurídico

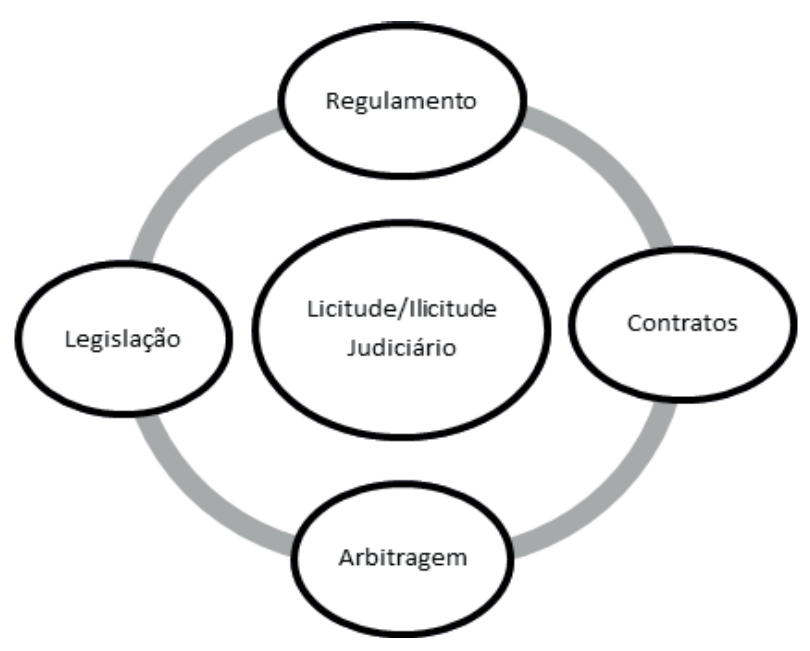


Figura 2 - Periferia "lex mercatoria” do sistema jurídico

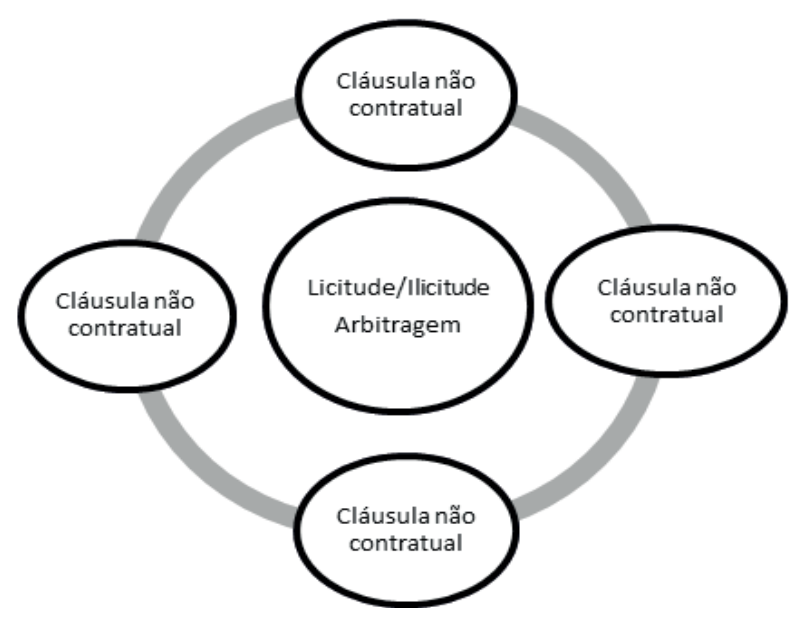

À luz desse entendimento e da compreensão de Teubner, a arbitragem deveria ser considerada o centro da periferia no que diz respeito ao núcleo decisional dos contratos de comércio internacional. Ocorreria, então, um processo de re-entry, ou seja, de reimersão no próprio sistema jurídico, o que possibilitaria operar na periferia do sistema os códigos e programas integrantes do seu núcleo.

\section{Três questões centrais a serem respondidas sobre lex mercatoria e arbitragem interna- cional}

Já havia sido mencionado na introdução deste trabalho que Gunther Teubner utilizou-se, para sua reflexão acerca da lex mercatoria, de alguns problemas que deveriam ser enfrentados pelo magistrado da Suprema Corte francesa para a internalização, no território da França e na respectiva jurisdição estatal, de uma decisão proferida por corte arbitral que adotou por fundamento decisional os usos do comércio internacional, ou seja, a lex mercatoria.

Afinal, (i) a lex mercatoria é um modelo aceitável de ordem jurídica? De acordo com a proposta de Teubner, sim. Para ele, a ordem jurídica não decorre, exclusivamente, da atuação legislativa estatal, senão das comunicações conscientes e racionais dos fatos da vida, a evidenciar acoplamentos de estruturas, irritações no interior do sistema jurídico e, consequentemente, a sua atuação reflexiva, autorreprodutiva, autopoiética. Esse entendimento, embora tenha sido delimitado no texto "Breaking Frames: Economic Gobalisation and the Emer- gence of the lex mercatoria", encontra-se também registrado no texto "A Bukowina Global sobre a Emergência de um Pluralismo Jurídico Transnacional", especificamente, quando reconhece a existência de um direito vivo e do pluralismo jurídico como formas de explicar certos fenômenos da globalização.

Ademais, (ii) como identificar normas jurídicas válidas e aplicáveis na estrutura da lex mercatoria? Teubner propõe o rompimento com a ideia de que o sistema jurídico é fechado em seus próprios elementos. Haveria, assim, a necessidade de permitir a realização de interações entre sistemas e de acoplamento entre estruturas que tenham alguma relação. No caso dos contratos de comércio internacional, como já dito anteriormente, esse acoplamento evidenciaria a existência da interação entre os sistemas jurídico e econômico.

Finalmente, (iii) qual a origem da lex mercatoria? Teubner indica, primeiramente, que os usos e costumes do comércio internacional acarretaram a estandardização de práticas comerciais, e que essas práticas culminam na validação interna dessa parte periférica do sistema jurídico. Infere, ainda, que o magistrado deve admitir que o direito, vale dizer, que o sistema jurídico não se encerra em si mesmo, mas admite interações, diálogo e contribuições.

Conforme conclusões acima traçadas por Teubner, seria possível que a Suprema Corte francesa internalizasse a decisão proferida pela corte arbitral com fundamento na lex mercatoria. Ocorre, contudo, que as questões referenciadas por Teubner, embora afastem a violação à critériorialidade e, de fonte normativa, não mencionem qualquer reflexão acerca de eventual dano à experiência democrática. Para suprir essa lacuna, tentaremos empreender essa investigação adiante.

\section{Validação e legitimação da arbitragem inter- nacional fundada na lex mercatoria: experi- ência democrática?}

O debate acerca da lex mercatoria, qualquer que seja a linha proposta para a abordagem, tende a ser demasiado teórico, acadêmico. Assim, tende a ser, igualmente, com as teorias que possuem justificação exclusiva em fundamentos sociais sem qualquer análise concreta, que busque acentar suas concluões em fundamentos empíricos ou de alguma forma perceptíveis. Conquanto seja salutar e saudável discutir as bases de um determinado 
setor da sociedade, como é o caso do setor normativo, não é indicado que tal seja realizado sem que se debruce sobre a realidade que nos é apresentada pela experiência e vivência cotidianas.

A análise ora empreendida reporta-se à adoção de normas costumeiras e assenta-se em usos e práticas do comércio transnacional, para a condução de negociações e para a resolução de conflitos - nesse caso, por meio de procedimentos arbitrais. A resolução de conflitos com fundamento em tais usos e costumes do comércio transnacional não deve olvidar as consequências que podem implicar para as esferas internas de Estados soberanos eventualmente envolvidos no ambiente negocial ou que podem sofrer com reflexos econômicos indiretos.

A instauração de uma corte arbitral internacional pressupõe a observância de diretrizes mínimas, como é o caso da Convenção de Viena sobre Contratos de Compra e Venda Internacional de Mercadorias (CISG), produzida sob a coordenação da UNCITRAL e que foi firmada em 11 de abril de 1980. No Brasil, a CISG foi introduzida pela promulgação do Decreto 8.327, de 2014. Na CISG estão estabelecidos, dentre outros, princípios que delimitam a competência da corte arbitral e os procedimentos de execução forçada da decisão pelo tribunal de arbitragem - enforcement.

A efetiva adesão do Brasil à CISG, ocorrida em março de 2013, está na esteira da promulgação e internalização da Convenção de Nova Iorque sobre o Reconhecimento e a Execução de Sentenças Arbitrais Estrangeiras, ocorrida por meio do Decreto 4.311, de 2002. Não obstante o lapso temporal superior a 10 anos, o objetivo das mencionadas convenções acaba por se alinhar no intuito de dar efetividade, no Brasil, às decisões proferidas por tribunais arbitrais, especialmente em sede de discussões acerca do comércio internacional. Quer parecer que o movimento de internalização, no e pelo Brasil, das diretrizes gerais em termos de arbitragem internacional e o seu reconhecimento pelas instituições jurisdicionais demonstra a opção política soberana - soberania externa - de reconhecer a legitimidade do procedimento de resolução de conflitos. No exercício da soberania interna, a opção é também percebida de forma clara a partir da edição da Lei 9.307, de 1996, recentemente alterada pela Lei 13.129, de 2015.

No ponto, as decisões proferidas por cortes arbitrais, para eventual cumprimento na jurisdição territorial brasileira, prescindiriam de maiores discussões quanto à sua validade e legitimidade. $\mathrm{O}$ mesmo entendimento ten- de a ocorrer quando, em vista decisões fundamentadas exclusivamente na lex mercatoria, afinal, podem as partes convencionar que a arbitragem se realize com base nas regras internacionais de comércio e que as decisões sejam reconhecidas ou executadas no Brasil em decorrência e nos termos de tratados internacionais do qual é signatário. ${ }^{19}$ Isso porque "a lex mercatoria pode ser invocada tanto nas arbitragens internas quanto nas internacionais" ${ }^{20}$, uma vez que a legislação brasileira não distingue as esferas territoriais de arbitragem.

Já foi dito que, para a finalidade desta reflexão, é admitida a produção de normas fora dos limites de atuação legislativa soberana de um determinado Estado. Tal entendimento indica a não ocorrência de violação a princípios que orientam a existência de soberania absoluta, como é o caso do princípio das fontes e da hierarquia normativa, especialmente porque, no ambiente de relações globalizadas transnacionais, de característica apátrida, há constante interação entre agentes comerciais de distintas jurisdições. E é essa constante interação que tende a manter a dinâmica do setor.

Não obstante o reconhecimento da dinâmica do comércio internacional, assentado em bases tradicionais imemoriais, o Estado brasileiro não pode desconsiderar o seu pacto interno para prestigiar o cumprimento de comandos decisionais proferidos por autoridades externas. Há de se resguardar as situações em que os usos e práticas do comércio internacional utilizados para a fundamentação de decisões arbitrais colidam com diretrizes fundamentais do Estado brasileiro e das normas internas que pressupõem a estabilização de relações jurídicas, em especial quanto à função social e ambiental dos contratos e ao seu equilíbrio material (direitos e deveres assumidos).

19 Destaque para os artigos $2^{\circ}, \$ 2^{\circ}$, e 34 da Lei 9.307 , de 1996 : "Art. $2^{\circ} \mathrm{A}$ arbitragem poderá ser de direito ou de eqüidade, a critério das partes. [...] $\$ 2^{\circ}$ Poderão, também, as partes convencionar que a arbitragem se realize com base nos princípios gerais de direito, nos usos e costumes e nas regras internacionais de comércio." "Art. 34. A sentença arbitral estrangeira será reconhecida ou executada no Brasil de conformidade com os tratados internacionais com eficácia no ordenamento interno e, na sua ausência, estritamente de acordo com os termos desta Lei." BRASIL. Lei $n^{\circ}$ 9.307, de 23 de setembro de 1996. Dispõe sobre a arbitragem. Disponível em: <http://www.planalto.gov.br/ccivil_03/leis/ L9307.htm>. Acesso em: 27 ago. 2015.

20 CRISTÓFARO, Pedro Paulo. A lex mercatoria e o direito brasileiro. In: FERRAZ, Rafaella; MUNIZ, Joaquim de Paiva (Coord). Arbitragem doméstica e internacional: estudos em homenagem ao prof. Theóphilo de Azeredo Santos. Rio de Janeiro: Forense, 2008, p. 323. 
As decisões arbitrais poderiam, com base no entendimento aqui defendido, adotar por fundamento os usos do comércio internacional, da lex mercatoria aplicada para a resolução de conflitos do comércio internacional. A sua internalização para cumprimento em jurisdições soberanas específicas pode, igualmente, ser considerada possível, tanto mais quando a validade e a legitimidade dos comandos comportam presunção decorrente da adesão a convenções internacionais - como é o caso do Brasil. Os limites que se estabelecem, contudo, têm a ver com a estrutura que constitui o Estado soberano, de modo que os comandos arbitrais não confrontem fundamentos essenciais dos Estados em que o enforcement deva ser realizado.

\section{Um parêntese: a tendência do discurso jurí- dico}

Um dos paradoxos do Direito, sobretudo em sistemas de civil law, consiste, exatamente, no fato de que se perpetuam as discussões acerca das situações e instituições sem que haja relevante reflexão ou investigação no que diz respeito à eficiência das instituições e da experiência prática - fruição empírica - de direitos subjetivos. Isso é reflexo do fato de que o direito brasileiro é legatário da tradição discursiva germânica à linha da jurisprudência dos conceitos desenvolvida por Friedrich Carl von Savigny e da perpetuação de situações mantidas pela antiga e pela atual "aristocracia”. Esses legados são tratados por Marcus Faro de Castro como portadores de um efetivo fechamento conceitual para o estudo do direito.

O direito constitucional brasileiro contemporâneo é legatário de uma antiga tradição. [...]

O fechamento conceitual das noções formalistas de direito subjetivo, incluindo os presentes implícita ou explicitamente nas constituições (e que por isso passam a ser tratados como direitos constitucionais ou fundamentais) parece evidente. Sendo tais direitos tratados como formas jurídicas com conteúdos "prontos", "completos", "inalteráveis", fica excluída a possibilidade de construção e reconstrução contínua desses conteúdos, mediante o debate democrático com prática institucional caracteristicamente conflitiva e reiterativa, capaz de alterar radicalmente, e sempre que for conveniente, concepções normativas antigas sobre direitos para adotar novas. $[\ldots]$

O "fechamento conceitual" desses legados incorporados ao direito constitucional - e inclusi- ve ao direito da Constituição brasileira de 1988 - é impeditivo de que os juristas, ao tratarem da constituição, trabalhem no sentido de valorizar o sentimento de liberdade de cada um e tenham, com base nisso, uma atuação inteligentemente transformadora da estrutura institucional da sociedade. ${ }^{21}$

$\mathrm{O}$ amadurecimento do debate jurídico aproxima-se da necessidade de flexibilização de conceitos supostamente rígidos, da interação de instituições e categorias jurídicas com instituições e categorias de outros ramos de análise da vida em sociedade, e da observância de uma efetiva fruição de direitos.

Esse "parêntese" no objeto deste texto, conquanto desconexo da sua análise central, tem por objeto tentar direcionar a discussão acerca da lex mercatoria para um foco que considere direitos sensíveis e a dinâmica dos setores envolvidos na discussão. No caso vertente, o foco mais específico está no direito de acesso a instituições que sejam efetivamente democráticas e que objetivem garantir experiências desenvolvimentistas. Pode-se indagar, assim, se a concepção de lex mercatoria adotada por Gunther Teubner, decorrente da estrutura teórica de Niklas Luhmann, seria legatária do velho discurso jurídico ou seria portadora de instrumentos que assegurassem, ou pelo menos possibilitassem, a fruição do direito à democracia.

A abordagem trazida a lume por Gunther Teubner no texto referenciado no presente trabalho quer parecer abrir um espaço positivo no discurso jurídico, na medida em que admite e se reporta ao pluralismo jurídico e à existência de uma ordem jurídica transnacional e não hierárquica. A estrutura do discurso fundado na teoria dos sistemas de Niklas Luhmann quer parecer ser mensageira não de uma velha forma de análise e de argumentação jurídica, mas de uma orientação teórica que se apresenta consideravelmente rígida em suas concepções e que não se utiliza de dados colhidos da experiência social prática, tanto mais porque se arrima em estudos oriundos da biologia ${ }^{22}$. Esse costuma ser um perfil comum às

21 Excerto do artigo Globalização, democracia e direito constitucional: legados recebidos e possibilidades de mudança. CASTRO, Marcus Faro de. Globalização, democracia e direito constitucional: legados recebidos e possibilidades de mudança. In: CLĖVE, Clèmerson Merlin; FREIRE, Alexandre (Coord.). Direitos fundamentais e jurisdição constitucional: análise, crítica e contribuições. São Paulo: Revista dos Tribunais, 2014. p. 697-719. p. 701; 704.

22 A estrutura da teoria dos sistemas desenvolvida por Niklas Luhmann e encampada por Gunther Teubner encontra suporte nos trabalhos desenvolvidos pelos biólogos chilenos Francisco Varela e Humberto Maturana. 
denominadas teorias sociais que observam e justificam estruturas e sistemas sem voltar os olhos para o efetivo acesso a direitos.

\section{Considerações finais: "direito vivo" como usos e costumes}

Este trabalho objetivou empreender análise da utilização da lex mercatoria em procedimentos de arbitragem transnacional. Não obstante a referência primeira tenha partido das reflexões de Gunther Teubner acerca da estrutura da lex mercatoria enquanto um subsistema do sistema jurídico - adotando por referência expressa a teoria dos sistemas de Niklas Luhmann -, o texto procurou confrontar a fundamentação de decisões em usos e costumes do comércio transnacional com a experiência democrática e institucional de Estado soberanos.

Quer parecer relevante considerar que o Direito não ostenta, necessariamente, a qualidade de algo "vivo", mas apenas de algo dinâmico. O que vive, em verdade, são as pessoas; as pessoas operam as instituições. O comércio transnacional constitui instituição inserida em ambiente de mercado e, como tal, é conduzido por meio da atuação de pessoas. São as pessoas, portanto, que, desde tempos imemoriais, criam e estabelecem usos e práticas, inclusive no que se refere às práticas do comércio internacional. Tais usos e práticas passam a integrar uma cadeia de costumes, de tradições. É desses costumes e tradições que decorre a moralidade das práticas entendidas como adequadas. Vale lembrar que o vocábulo "moral" possui raiz em mores, que no latim significa "relativo aos costumes". Moral, pois, não é algo institucionalizado, como tende a ser Direito, mas apenas socializado. Isso, contudo, não retira dos usos e costumes que integram a lex mercatoria a possibilidade de serem adotados como fundamentos decisionais de conflitos ou balizadores de negociações no comércio transnacional.

A lex mercatoria é "viva". Traz em si noções intersubjetivas que não estão ligadas a nenhuma jurisdição específica, embora possa ser utilizada por todos que estão inseridos no âmbito do comércio transnacional, e possui o dinamismo suficiente para fomentar a constante atualização do setor em que inserida. A expansão da comunicação e o incremento das relações comerciais não podem, jamais, ser acompanhadas pelo Direito institucionalizado, mas podem sê-lo pelos usos e práticas. É daí que se extrai, em essência, a carga essencial da lex mercatoria enquanto soft law: garantir, fora das amarras estatais, estabilidade nas relações comerciais transnacionais e permitir a padronização de procedimentos que, apátridas e não pertencentes a qualquer jurisdição, possibilitem facilitar as relações comerciais.

Eventuais entraves à utilização da lex mercatória ou decorrentes da sua aplicação tendem a clamar, pois, por foro próprio, especializado. Nesse sentido, se situam as cortes internacionais. A adoção de critérios técnicos setoriais não pode, fundamentalmente, retirar a validade e a legitimidade das decisões arbitrais. Pelo contrário, tais qualidades são presumidas em especial pelos países signatários de tratados e convenções internacionais sobre comércio internacional e sobre arbitragem - como é o caso do Brasil. Não haveria de se falar, em princípio, na limitação ou na violação da experiência democrática em razão da prolação e da execução de sentença arbitral internacional fundada apenas nos usos e costumes do comércio internacional, tanto mais porque a democracia se expressa também pela qualidade na resolução de conflitos. Somente algum abalo essencial do pacto fundamental é que poderia ser oposto ao enforcement do comando arbitral.

\section{Referências}

BEAWES, Wyndham Kent; MORTIMER, Thomas. Lex mercatória rediviva: or, the Merchant's directory. London: J. Rivington, and Sons, 1754.

BRASIL. Decreto no 4.311, de 23 de julho de 2002. Promulga a Convenção sobre o Reconhecimento e a Execução de Sentenças Arbitrais Estrangeiras. Disponível em: <http:// www.planalto.gov.br/ccivil_03/decreto/2002/D4311. htm>. Acesso em: 27 ago. 2015.

BRASIL. Decreto $n^{\circ} 8.327$, de 16 de outubro de 2014. Promulga a Convenção das Nações Unidas sobre Contratos de Compra e Venda Internacional de Mercadorias - Uncitral, firmada pela República Federativa do Brasil, em Viena, em 11 de abril de 1980. Disponível em: <http:// www.planalto.gov.br/ccivil_03/_Ato2011-2014/2014/Decreto/D8327.htm>. Acesso em: 27 ago. 2015.

BRASIL. Lei no 9.307, de 23 de setembro de 1996. Dispõe sobre a arbitragem. Disponível em: <http://www.planalto. gov.br/ccivil_03/leis/L9307.htm>. Acesso em: 27 ago. 2015. 
BRASIL. Lei $n^{\circ} 13.129$, de 26 de maio de 2015. Altera a Lei no 9.307, de 23 de setembro de 1996, e a Lei no 6.404, de 15 de dezembro de 1976, para ampliar o âmbito de aplicação da arbitragem e dispor sobre a escolha dos árbitros quando as partes recorrem a órgão arbitral, a interrupção da prescrição pela instituição da arbitragem, a concessão de tutelas cautelares e de urgência nos casos de arbitragem, a carta arbitral e a sentença arbitral, e revoga dispositivos da Lei no 9.307, de 23 de setembro de 1996. Disponível em: <http://www.planalto.gov.br/ccivil_03/_Ato20152018/2015/Lei/L13129.htm>. Acesso em: 27 ago. 2015.

CASTRO, Marcus Faro de. Globalização, democracia e direito constitucional: legados recebidos e possibilidades de mudança. In: CLÈVE, Clèmerson Merlin; FREIRE, Alexandre (Coord.). Direitos fundamentais e jurisdição constitucional: análise, crítica e contribuições. São Paulo: Revista dos Tribunais, 2014. p. 697-719.

CRISTÓFARO, Pedro Paulo. A lex mercatoria e o direito brasileiro. In: FERRAZ, Rafaella; MUNIZ, Joaquim de Paiva (Coord). Arbitragem doméstica e internacional: estudos em homenagem ao prof. Theóphilo de Azeredo Santos. Rio de Janeiro: Forense, 2008.

FERRAZ, Rafaella; MUNIZ, Joaquim de Paiva (Coord). Arbitragem doméstica e internacional: estudos em homenagem ao prof. Theóphilo de Azeredo Santos. Rio de Janeiro: Forense, 2008.

MENDES, Rodrigo Octávio Broglia. Arbitragem, lex mercatoria e direito estatal: uma análise dos conflitos ortogonais do direito transnacional. São Paulo: Quartier Latin, 2010.

NALIN, Paulo; STEINER, Renata C.; XAVIER, Luciana Pedroso (Coord.). Compra e venda internacional de mercadorias: vigência, aplicação e operação da CISG no Brasil. Curitiba: Juruá, 2014.
NEVES, Marcelo. Transconstitucionalismo. São Paulo: M. Fontes, 2009.

PINHEIRO, Luís de Lima. Arbitragem transnacional: a determinação do estatuto da arbitragem. Coimbra: Almedina, 2005.

TEUBNER, Gunther. A Bukowina global sobre a emergência de um pluralismo jurídico transnacional. Impulso, Piracicaba, v. 14, n. 33, p. 9-31, 2013. Disponível em: $<$ http://www.unimep.br/phpg/editora/revistaspdf/imp33art01.pdf >. Acesso em: 29 jul. 2015.

TEUBNER, Gunther. Breaking frames: economic globalization and the emergence of Lex mercatoria. European Journal of Social Theory, Liverpool, v. 5, n. 2, p. 199-217. May, 2002. Disponível em: <http://papers.ssrn.com/sol3/ papers.cfm?abstract_id=893143 $>$. Acesso em: 29 jun. 2015.

TEUBNER, Gunther. Global Bukowina: legal pluralism in the world-society. In: (Ed.). Global law without a state. Aldershot: Dartmouth, 1996. p. 3-28. Disponível em: <http://papers.ssrn.com/sol3/papers.cfm?abstract_ id=896478>. Acesso em: 29 jun. 2015.

VICENTE, Dario Moura. Da arbitragem comercial internacional: direito aplicável ao mérito da causa. Coimbra: Coimbra, 1990.

WALD, Arnoldo; LEMES, Selma Ferreira (Coord.). Arbitragem comercial internacional: a Convenção de Nova Iorque e o direito brasileiro. São Paulo: Saraiva, 2011. 